\title{
Relationship of self-perception between the prevalence of malocclusions and the need for orthodontic treatment in I2-year-old school children
}

\begin{abstract}
Objective: To determine the relation of self-perception of the need for orthodontic treatment of malocclusion with the prevalence in schoolchildren aged 12 years in the Baños parish of the city of Cuenca 2016

Materials and methods: EPI INFO version 7.2, free access, THUS Obtaining a sample of 103 pieces Consisting of five parts, the first overall patient data, the second data Oral Hygiene index, the index DMFT third tooth decay, periodontal disease index the fourth and the fifth of Russel malocclusion index Through the retrospective method.

Results: The prevalence of malocclusions was $96 \%$ in relation to the normoclusion, which was $4 \%$. In the prevalence of self-perceived need for orthodontic treatment the majority of the population indicated that they needed orthodontic treatment in $74 \%$, $26 \%$ compared to $\mathrm{WHO}^{1}$ did not indicated that need orthodontic they treatment. In the relationship of self-perceived need for orthodontic treatment with the prevalence of malocclusion $75 \%$ of the population said they did not need orthodontic treatment, but had some type of malocclusion compared to $25 \%$ who said they need orthodontic treatment and had some kind of malocclusion.
\end{abstract}

Volume I Issue 5 - 2018

Carlos Segundo Quille Uguña,' Ronald

Ramos Roossevelt Montiel, ${ }^{2}$ Miriam

Fernanda Ortega López, ${ }^{3}$ Gladys del Cisne

Jumbo Tinitana ${ }^{3}$

'Dentist General Catholic, University of Cuenca, Ecuador

${ }^{2}$ General Dentist, Orthodontics Specialist, Professor of undergraduate Catholic University of Cuenca, Professor of postgraduate University of Guayaquil, Ecuador

${ }^{3}$ Dentist General Catholic, University of Cuenca, Ecuador

Correspondence: Ronald Ramos RM, General Dentist, Higher Diploma in Comprehensive Dentistry, Orthodontics Specialist. PhD Student University of Zulia Maracaibo Venezuela, Professor of graduate University of Guayaquil,Teacher Grade Catholic University of Cuenca, Ecuador, Email ronald mtz@hotmail.com

Received: August 3I, 2018 | Published: September 21, 2018

Keywords: malocclusion, orthodontics, prevalence, aesthetics

\section{Introduction}

Although malocclusion is one of the less knowledge of oral diseases for the population worldwide, in the stomatological field it is one of the most prevalent oral alterations after periodonta ${ }^{2,3}$ decay and disease. Problems malocclusion can be given by the sum of several etiologic factors, these factors will cause a disharmony in the oral cavity, the same can include aesthetics of the patient or even problems at the language level, mastication, and swallowing dysfunction $\mathrm{ATM}^{4}$ level. These alterations can be observed more frequently in civilizations that over time have been affected by the global development due to the change in the type of food, population change agricultural to rural areas, the forces used to chew food and other factors that in one way or another influenced occlusion actual population. More than that people with problems of malocclusion present alterations in aesthetics and function hand, we also see affected the psychosocial status of individuo. ${ }^{5,6}$ That is why it is advisable to start treatment at an early age, to avoid such disturbance affecting the individual during childhood both the emotional level as Care. ${ }^{6}$ As a solution to correct such alterations, orthopedic treatments more than help correct the position of the teeth and / or jaws used parts, it helps us improve facial proportions of individuo. ${ }^{6}$ The patient's perception will be paramount for the implementation of appropriate treatment and helps professionals to make decisions about the type of treatment to be performed in order to find comfort and acceptance by the patient.? Globally we say that the behavior of malocclusions is in ranges from $35 \%$ to $75 \%{ }^{8}$ To give an accurate diagnosis of malocclusions we need to assess dental, skeletal muscle and the stomatognathic system as well as the psychological state and social environment patient ${ }^{9}$ factors.
For that reason we have been obliged to conduct an epidemiological study to establish self-perceived need for orthodontic treatment and the prevalence of malocclusions present the population of 12 years and thus to establish in future programs help us prevent and combat malocclusions school population level. Therefore, we as dentists must have the necessary skills to assess, diagnose and establish a correct treatment plan. This study is framed in the research of self-perception and prevalence and corresponds to the specialty of orthodontics. He performed it with medical records of 12 children who attend schools in the parish baths and rest in the database of the research department faculty of health and welfare of the Catholic University of Cuenca with prior authorization and knowledge of their representatives.

\section{Materials and methods}

The design of this study was documentary, observational and retrospective. Clinical examination was performed school children who have twelve years of age or older or who are about to turn thirteen, both male and female and are enrolled in schools belonging to the parish baths in the city of Cuenca, stated in the database research Department of the Faculty of Health and Welfare of the Catholic University of Cuenca. A study population comprised 103 schoolchildren corresponding to male and female, the study sample consisted of $100 \%$ of the population considered; consent forms to parents indicating the review methodology, based on ethical principles extremely important autonomy and justice in developing and making morally valid clinical decisions and settlements were also awarded to school was sent, the same as presented test day with the signing of aprobación. ${ }^{7,8}$ To determine the prevalence of malocclusions extra and 
intraoral examination was performed, in which the anteroposterior profile was evaluated by analyzing three anatomical points are: glabella, pogonion subnasal and soft tissue; the vertical profile was assessed with the camper plane and mandibular plane. In the intraoral examination canine relationship and right and left, overjet and overbite molar ratio it was studied; for analysis of crowding and diastemas was assessed individually to each tooth way and thus determine their presence and severity. To register the presence of crossbite, posterior or anterior open bite dental arches in occlusion was analyzed, allowing determine these changes in normal occlusion; It could also be recorded if there was a deviation from the midline, in which the upper dental midline does not match the lower dental midline. The findings described above possible to reach a presumptive diagnosis of malocclusion according to Angle classification, the same as was recorded in the epidemiological profile. The IONT index, specifically its aesthetic component (AC), itself consisting of a scale of 10 intraoral photographs still picture 1 has the lowest degree of malocclusion and the picture 10 was used to establish self-perceived orthodontic treatment need greater condition dental malocclusions and less attractive, he indicated the school you select the photograph that identifies your dental attractive, without influencing the opinion of a third party, allowing self to find the prevalence of malocclusion received 6.7; finally the recording of information was performed on the database program EPI INFO, version 7.2. CDC Atlanta. The prevalence of the disease was calculated using the following formula:

$$
\text { Prevalence }=\frac{\text { number of patients }}{\text { number examined }}
$$

Then he grouped by sex and same calculation was performed.

\section{Discussion}

This study was conducted at the school for 12 years in the parish bathrooms, with a total of 103 samples from school female and male. And the prevalence of malocclusions self-perceived need for treatment of each, and their relationship was studied. After analyzing all data prevalence of malocclusions in 99 (96\%) of chips and a normoclusion only 4 (4\%) of the total sample it was obtained. These values are similar to those obtained by Del Castillo ${ }^{10}$ which a sample of 201 schools obtained a prevalence of $85.6 \%$ malocclusions. Unlike Pino Roman \& Cols ${ }^{11}$ where it received a prevalence of $58.2 \%$ malocclusions. According to sex this research obtained in females there is a prevalence of malocclusions of $56(95 \%)$ and a normoclusion $3(5 \%)$, and the male prevalence of malocclusions of 43 (98\%) and normoclusion $1(2 \%)$ of the sample according to sex (Table 3). Similar to those obtained by Calzada Baldomo ${ }^{8}$ in a sample of 113 schoolchildren with a higher prevalence of malocclusions for males $54.8 \%$ compared with $45.1 \%$ female. Unlike the study by Murrieta Pruneda et al. ${ }^{12}$ where it received a higher prevalence of malocclusions in females with $54.2 \%$ compared to $32.6 \%$ male with the total sample. Regarding necesida orthodontic treatment in this study $76(74 \%)$ of the total sample requires orthodontic treatment, while $27(26 \%)$ do not. Cartes Velasquez et al. ${ }^{2}$ indicate that the total school examined $67.4 \%$ of school need orotdòntico treatment, while $32.6 \%$ do not. Unlike Arroyo Araya et al. ${ }^{4}$ in which a sample of 195 children aged 8 to 12 years was found that $23.8 \%$ of children in need of orthodontic treatment and $67.4 \%$ did not need it. With regard to the perceived need for orthodontic treatment according to sex, we can mention that females have a greater need for orthodontic treatment conducted with $78 \%$ of the sample, compared to males where the total chips male school $68 \%$ indicates a need orthodontic treatment. Similar to the study of Cartes Velasquez et al. ${ }^{2}$ where the self-image questionnaire mention the female feel like you have some type of malocclusion in a higher percentage $81.2 \%$ compared with $69.2 \%$ male with sample. Unlike road Baldomo points where a greater need in the female orthodontic treatment performed with a $60.9 \%$ to $56 \%$ for males. According to the index of orthodontic treatment need (IONT) in this study $55 \%$ of the examined chips had a higher percentage of need for orthodontic treatment at a moderate level, followed by a level of slight $26 \%$ need and a great need to $18 \%$ of the total sample. Similar to the studies by Martin Cristina et al. ${ }^{13}$ where a sample of 203 children obtained a higher rate in the moderate level of need for treatment with $44.28 \%$ of the sample, followed by a slight need treatment and finally a great need for treatment. Unlike Pardo Villar et al. ${ }^{14}$ where obtained from a sample of 210 schoolchildren a great need for orthodontic treatment $73.3 \%$ of the total sample. Levels in need IONT females had a higher percentage in moderate $59 \%$, as male with $50 \%$ of the sample. Similar to that obtained by Mafla Ana Cristina et al. ${ }^{15}$ with higher percentages in moderate $35.6 \%$. Unlike Amador Lazo et al ${ }^{16}$ where he obtained higher percentages need for treatment in mild level for both sexes.

Finally needs to relate perceived orthodontic treatment and the presence of malocclusions we could see that $74(75 \%)$ of chips that have malocclusions manifested not need treatment, while $25(25 \%)$ if I need it. Unlike the study by Cristina Martìn et a ${ }^{12}$ where the school manifest a high percentage of dissatisfied with the position of the teeth of their children and express a desire to receive orthodontic treatment. According to sex we have $46(78 \%)$ of chips school orthodontic treatment of which $45(76 \%)$ had malocclusions manifested necessary, while in $13(22 \%)$ of the chips school expressed not need treatment orthodontic of which $11(19 \%)$ had some type of malocclusion. For males in $30(68 \%)$ of chips, the school said need orthodontic treatment of the 29 which $(66 \%)$ had some type of malocclusion, while those who said they did not need orthodontic treatment 14 (32\%) had malocclusions . Unlike the values obtained by Riera Garcia et al. ${ }^{17}$ where a sample of 241 schools that obtained for $15 \%$ female school said need orthodontic treatment of which $14 \%$ had some type of malocclusion.

\section{Results}

This study was conducted with epidemiological data schoolchildren aged 12 parish Bathrooms, found in the record of the research department of the Faculty of Dentistry at the Catholic University of Cuenca, registering the following results:

a. The total sample examined $57 \%$ of chips belonged to school female and $43 \%$ male school children (Table 1) (Table 2).

b. The prevalence of malocclusion was $96 \%$ and $4 \%$ of the same showed normoclusion (Table 3).

c. According to sex it was obtained that $95 \%$ of females had chips malocclusions while $5 \%$ had normoclusion while in males showed $98 \%$ and $2 \%$ malocclusions normoclusion presented.

d. With regard to self-perceived orthodontic treatment $74 \%$ of examined records needed orthodontic treatment and $26 \%$ ) did not need orthodontic treatment (Table 4).

e. According to sex $78 \%$ of female tokens needed orthodontic treatment and $22 \%$ did not need orthodontic treatment; in males $68 \%$ of chips needed orthodontic treatment and $32 \%$ did not need (Table 5) (Table 6). 
f. According to the indices of orthodontic treatment need $18 \%$ of chips had a great need for orthodontic treatment, followed by a slight need for orthodontic treatment with $26 \%$ and $55 \%$ with a moderate need for orthodontic treatment (Table 7) (Table 8). g. According to the relationship between self-perception and prevalence of malocclusions $75 \%$ of chips presence of malocclusions not need orthodontic treatment, while $25 \%$ if required (Table 9).

Table I Sample distribution according to sex

\begin{tabular}{lll}
\hline Sex & n & $\%$ \\
\hline Female & 59 & $57 \%$ \\
Male & 44 & $43 \%$ \\
Grand Total & 103 & $100 \%$ \\
\hline
\end{tabular}

Interpretation of the table:The sample was divided in 59 (57\%) of school female sex and $44(43 \%)$ for school male.

Table 2 Prevalence of malocclusion in the population

\begin{tabular}{lll}
\hline Prevalence malocclusion & $\mathbf{n}$ & $\%$ \\
\hline Malocclusion & 99 & $96 \%$ \\
normoclusion & 4 & $4 \%$ \\
Grand Total & 103 & $100 \%$ \\
\hline
\end{tabular}

Interpretation of the table: population with malocclusion with $99 \%$ compared to normoclusion $4 \%$.

Table 3 Prevalence of malocclusion in the population according to sex

\begin{tabular}{llllllll}
\hline \multirow{2}{*}{ Sign distribution agreement to sex } & \multicolumn{2}{c}{ Female } & \multicolumn{2}{c}{ Male } & \multicolumn{2}{c}{ Grand Total } \\
& $\mathbf{n}$ & $\%$ & $\mathbf{n}$ & $\%$ & $\mathbf{n}$ & $\%$ \\
\hline Malocclusion & 56 & $95 \%$ & 43 & $98 \%$ & 99 & $96 \%$ \\
Normoclusion & 3 & $5 \%$ & I & $2 \%$ & 4 & $4 \%$ \\
Grand Total & 59 & & 44 & & 103 & $100 \%$ \\
\hline
\end{tabular}

Interpretation of the table: The female has a higher percentage of malocclusion $57 \%$, as a normoclusion $75 \%$.

Table 4 Prevalence of perception of the need for treatment

\begin{tabular}{lll}
\hline Prevalence of self-perception & $\mathbf{n}$ & $\%$ \\
\hline Needs to & 76 & $74 \%$ \\
Does not need & 27 & $26 \%$ \\
Grand Total & 103 & $100 \%$ \\
\hline
\end{tabular}

Interpretation of the table: we can see that $74 \%$ of the population needs orthodontic treatment

Table 5 Prevalence of self-perception of orthodontic treatment according to sex

\begin{tabular}{|c|c|c|c|c|c|c|}
\hline \multirow{2}{*}{ Prevalence of self-perception to the sex } & \multicolumn{2}{|c|}{ Female } & \multicolumn{2}{|c|}{ Male } & \multicolumn{2}{|c|}{ Grand Total } \\
\hline & $\mathbf{n}$ & $\%$ & $\mathbf{n}$ & $\%$ & $\mathbf{n}$ & $\%$ \\
\hline Needs to & 46 & $78 \%$ & 30 & $68 \%$ & 76 & $74 \%$ \\
\hline Does not need & 13 & $22 \%$ & 14 & $32 \%$ & 27 & $26 \%$ \\
\hline Grand Total & 59 & & 44 & & 103 & $100 \%$ \\
\hline
\end{tabular}

Interpretation of the table: $78 \%$ of female schoolchildren manifest need orthodontic treatment compared to $68 \%$ male 
Table 6 Severity levels of orthodontic treatment

\begin{tabular}{lll}
\hline Level orthodontic treatment need (IONT) & n & $\%$ \\
\hline Great need & 19 & $18 \%$ \\
Mild necesida & 27 & $26 \%$ \\
Moderate need & 57 & $55 \%$ \\
Grand Total & 103 & $100 \%$ \\
\hline
\end{tabular}

Interpretation of the table: $55 \%$ of the population exhibits a moderate need for orthodontic treatment, followed by a slight need $26 \%$ and a great need I $8 \%$.

Table 7 Severity levels of orthodontic treatment according to sex

\begin{tabular}{llllllll}
\hline & \multicolumn{2}{c}{ Female } & \multicolumn{2}{c}{ Male } & \multicolumn{2}{c}{ Grand Total } \\
Levels orthodontic treatment need (IONT) & $\mathbf{n}$ & $\%$ & $\mathbf{n}$ & $\%$ & $\mathbf{n}$ & $\%$ \\
\hline Great need & 11 & $19 \%$ & 8 & $18 \%$ & 19 & $18 \%$ \\
Mild necesida & 13 & $22 \%$ & 14 & $32 \%$ & 27 & $26 \%$ & $55 \%$ \\
Moderate need & 35 & $59 \%$ & 22 & $50 \%$ & 57 & & \\
Grand Total & 59 & & 44 & & 103 & $100 \%$ \\
\hline
\end{tabular}

Interpretation of the table:The moderate level of need is the largest population in need of orthodontic treatment states, with $59 \%$ for females and $50 \%$ for males.

Table 8 Relationship between self-perception and prevalence of malocclusions

\begin{tabular}{|c|c|c|c|c|c|c|}
\hline List of self-perception and presence of malocclusions & \multicolumn{2}{|c|}{ Malocclusion } & \multicolumn{2}{|c|}{ Normoclusion } & \multicolumn{2}{|c|}{ Grand Total } \\
\hline Needs to & 74 & $75 \%$ & 2 & $50 \%$ & 76 & $74 \%$ \\
\hline Does not need & 25 & $25 \%$ & 2 & $50 \%$ & 27 & $26 \%$ \\
\hline Grand Total & 99 & & 4 & & 103 & \\
\hline
\end{tabular}

Table interpretation: In people with malocclusion most $75 \%$ is required orthodontic treatment, while the population with normoclusion $50 \%$ needs and $50 \%$ do not need treatment.

Table 9 Relationship between self-perception and the presence of malocclusions by sex

\begin{tabular}{|c|c|c|c|c|c|c|}
\hline \multirow{2}{*}{$\begin{array}{l}\text { Relationship and presence malocclusions autpercepcón } \\
\text { according to sex }\end{array}$} & \multicolumn{2}{|c|}{ Female } & \multicolumn{2}{|c|}{ Male } & \multicolumn{2}{|c|}{ Grand total } \\
\hline & $\mathbf{n}$ & $\%$ & $\mathbf{n}$ & $\%$ & $\mathbf{n}$ & $\%$ \\
\hline Needs to & 46 & $78 \%$ & 30 & $68 \%$ & 76 & $74 \%$ \\
\hline Malocclusion & 4.5 & $76 \%$ & 29 & $66 \%$ & 74 & $72 \%$ \\
\hline Normoclusion & I & $2 \%$ & 1 & $2 \%$ & 2 & $2 \%$ \\
\hline Does not need & 13 & $22 \%$ & 14 & $32 \%$ & 27 & $26 \%$ \\
\hline Malocclusion & II & $19 \%$ & 14 & $32 \%$ & 25 & $24 \%$ \\
\hline Normoclusion & 2 & $3 \%$ & 0 & $0 \%$ & 2 & $2 \%$ \\
\hline Grand Total & 59 & & 44 & & 103 & \\
\hline
\end{tabular}

Interpretation of the table: In indicator requires orthodontic treatment observe a higher percentage among females with $78 \%$ to the male with $68 \%$ and malocclusion variable is the highest percentage obtained with $76 \%$ for females and $66 \%$ for females. The display does not need treatment malocclusions with a higher percentage of $19 \%$ followed by $24 \%$ female male

\section{Acknowledgements}

None.

\section{Conflict of interest}

Authors declare that there is no conflicto of interest.

\section{References}

1. WHO. Global problem of oral diseases. Geneva: Press; 2014

2. Ricardo CV, Eric A, Carolina V. Malocclusions and its impact on students pscicosocial an intercultural high school. Rev Int J Odontoest. 2010;4(1):65-70. 
3. Race X, Pinto G, Ayala E. Manual esducaión for oral health for teachers and promoters. MSP. 2010.

4. Yacsiry AA, Hector MH. Malocclusion in children 8 to 12 years and perception of parents need a consultation with the orthodontist at an early age. Rev Cient Odont. 2012;8(2):19-25.

5. Proffitt William FS. Orthodontic Conmtemporánea. 5th ed. Barcelona: Elsevier; 2014.

6. Myriam Sada GJ. Malocclusions and mixed dentition. An Peadtr Contin. 2006;4(1):66-70.

7. Feregrino Vejar, GRJ Lourdes. Perception and psychosocial effects of malocclusions. Rev Tamé. 2016;4(12):443-447.

8. Amaray $\mathrm{CB}$. Orthodontic treatment need index escolares. Aplicación need for tratameinto Shaw. Medisur Agost. 2014:12(4).

9. Queen YG. Presence of malocclusions in adolescents and their relationship with certain psychosocial factres. Rev Arch Medic. 2008:12(5).

10. Aliaga Arón MVMAdCR Castle. Malocclusions in children and adolescents ntivos communities and hamlets in the Amazon of Peru Ucayali. Rev Peru Med Exp Salud Pub. 2011;28(11).
11. Iraida María PR, Olga Lidia VC, Pablo Antonio GV. Malocclusions according to the index of dental aesthetics in seventh grade students of Santa Clara. Medicent Elect. 2014;18(4).

12. Martìn C. Prevalence of malocclusions in a group of Mexican and suposible relation to age, sex and socioeconomic status 2009. Fac Odont Univ Antóquia. 2012;24(1):121-132.

13. Cristina Martin, Cid EBLAMGSRRG. Prevalence of malocclusion of the autonomous community in Madrid and dental aesthetic index. Dialnet. 2009;39(2).

14. PardoVillar Katherine SSCPAK. Occlusal traits and self-perceived need for orthodontic treatment for Peruvian schoolchildren. Rev Kiru. 2014;11(2).

15. Alina Arocha, AGMPYGE Arzuaga. Malocclusion and habits deforming loops school with early mixed dentition. Medisan. 2016;20(4).

16. Lazo Amador Yaina CLY. Necesiadad orthodontic treatment in preuniversity students. Rev Cub Medic Milit. 2014;43(1).

17. Medina C. Prevalence of dental malocclusions in a group of pediatric patients. Act Odont Venezolana. 2010;48(1). 